\title{
A CIÊNCIA E A TECNOLOGIA COMO POSSIBILIDADES DE DESENVOLVIMENTO TECNOLÓGICO DA REGIÃO CENTRO-OESTE DO BRASIL
}

\author{
SCIENCE AND TECHNOLOGY AS POSSIBILITIES OF \\ TECHNOLOGICAL DEVELOPMENT IN THE MIDWEST OF BRAZIL
}

\section{LA CIENCIA Y LA TECNOLOGÍA COMO POSIBILIDADES DE DESARROLLO TECNOLÓGICO DE LA REGIÓN CENTRO-OESTE DE BRASIL}

\author{
Mateus Boldrine Abrita - Universidade Estadual de Mato Grosso do Sul - \\ Campo Grande - Mato Grosso do Sul - Brasil \\ mateusabrita@uems.br
}
Walter Guedes da Silva - Universidade Estadual de Mato Grosso do Sul -
Campo Grande - Mato Grosso do Sul - Brasil
guedes@uems.br

\section{Resumo}

Este trabalho discute 0 atual protagonismo da ciência e da tecnologia na Região Centro-0este (CO) como forma de impulsionar o desenvolvimento tecnológico nessa região e, também, fazer uma comparação com a realidade brasileira. Após a análise dos dados disponíveis no que diz respeito ao número de pesquisadores, instituições, artigos científicos publicados e número de doutores (ou seja, no lado "não produtivo no sentido econômico"), a região $\mathrm{CO}$ apresentou diversos avanços, inclusive na comparação relativa com o Brasil. Todavia, quando analisamos o setor produtivo, observamos que algumas mazelas presentes no âmbito nacional são, muitas vezes, piores no CO.

Palavras-chaves: Sistemas de inovação, Região Centro-0este, desenvolvimento tecnológico.

\section{Abstract}

This article discusses the current protagonism of science and technology in the Midwest Region, as a way to boost technological development in this region and, also, makes a comparison with the Brazilian reality. After analyzing the available data regarding the number of researchers, institutions, published scientific articles and number of Ph.D. personnel, (i.e., the "non-productive in economic sense"), the Midwest Region presented many advances, including when comparing with Brazil. However, when we analyze the productive sector, we observe that some problems present at a national level are often worse in the Midwest.

Keywords: Innovation systems, Midwest Region, Technological development.

\section{Resumen}

Este artículo discute el papel actual de la ciencia y tecnología en la Región Centro-0este de Brasil, como una forma de impulsar el desarrollo tecnológico en esta región, además, hacer una comparación con la realidad brasileña. Después del análisis de datos disponibles en lo que se refiere al número de investigadores, instituciones, artículos científicos publicados y número de doctores, o sea, en el lado "no productivo en el sentido económico ", la región Centro-0este presentó diversos avances, inclusive en la comparación relativa con Brasil. Sin embargo, cuando analizamos el sector productivo, observamos que algunos problemas presentes en el ámbito nacional son, a menudo, peores en el Centro-0este.

Palabras clave: Sistemas de innovación, Región Centro-0este, Desarrollo tecnológico. 


\section{Introdução}

O Brasil vem passando por transformações estruturais no âmbito de sua produção agroindustrial e com a Região Centro-Oeste (CO) não é diferente. No final dos anos 1960 e início dos anos 1970, o CO do Brasil veio se consolidando como região agroexportadora e consumidora de produtos industrializados. Esse processo obteve apoio e teve como plano de fundo o governo militar, que possuía uma narrativa de integração nacional e desenvolvimento com presença do Estado, também chamado de desenvolvimentismo. Passado esse processo de consolidação produtiva mais relacionado com o setor primário, outro caminho a ser percorrido pode ser por meio do direcionamento de incentivos que possibilitam mudanças na estrutura produtiva da região, objetivando um círculo virtuoso de crescimento. Essas mudanças devem buscar o incentivo aos mercados com complexidade tecnológica mais elevada e que possuem elevada elasticidade-renda da demanda interna e externa.

Os sistemas nacionais e regionais de inovação têm sido elemento basilar para o desenvolvimento dos países. Trabalhos como de Choi (2019) evidenciam essa argumentação. Os autores Wu e Wu (2017) apontam que o sistema nacional de inovação tem sido muito importante para o desenvolvimento chinês. Kwon e Motohashi (2017) analisam como os sistemas nacionais de inovação afetam a competitividade da indústria no Japão e Estados Unidos. Utilizando um método de simulação, os autores apontam que as inovações são cruciais para a competitividade e para as relações comerciais de longo prazo. Também Zang e Wang (2019) apontam que na era do big data, tecnologias da informação e comunicação e avanços na internet, os sistemas de inovação ganham destaque muito acentuado no que se refere ao crescimento econômico dos países.

Dessa perspectiva, o objetivo deste texto é discutir o atual protagonismo da ciência e da tecnologia na região CO a fim de observar a existência de um sistema de inovação capaz de impulsionar o desenvolvimento tecnológico na região, bem como fazer uma comparação com a realidade brasileira. Para tanto, partimos do princípio de que o crescimento econômico de uma determinada região - no atual modelo de avanço do sistema produtivo capitalista - é acompanhado de uma mudança estrutural produtiva, com incentivo a produtos e setores com conteúdos tecnológicos mais elevados alinhada às revoluções tecnológicas 
Assim, discutimos inicialmente aspectos teóricos como a importância da tecnologia para o crescimento econômico, as janelas de oportunidades para o crescimento que surgem por meio das revoluções tecnológicas, os sistemas de inovação e sua importância para o crescimento econômico. Posteriormente, apresentamos os dados disponíveis de ciência e tecnologia para a região CO, do setor produtivo e das atividades de inovação na região, bem como uma comparação com a realidade brasileira. Por fim, algumas considerações.

\section{Tecnologia, crescimento econômico e eficiência schumpeteriana}

Um autor seminal nos temas da tecnologia e crescimento econômico é Schumpeter (1911/1982), que destaca um caráter evolutivo do processo capitalista intrínseco oriundo da própria natureza do sistema. Desse modo, na gênese basilar do capitalismo estão os novos métodos de produção, mercado, consumo e organização industrial que a empresa capitalista gera permeada pela inovação. Assim, as inovações tecnológicas ganham destaque em relação ao crescimento econômico que pode servir de alicerce para um processo mais amplo como o desenvolvimento.

Uma mudança em termos qualitativos de transformação da estrutura produtiva de determinada região pode apresentar uma relação importante com o crescimento econômico regional. Schumpeter (1911/1982), por meio de sua análise de destruição criadora, demonstra a importância fundamental da mutação tecnológica no crescimento econômico capitalista. Assim, orientar a economia para setores específicos que geram externalidades e efeitos de transbordamentos positivos, empregos de alta qualidade e que elevam a produtividade, pode ser fundamental para o crescimento regional.

Autores como Dosi (1988) e Dosi, Pavitt e Soete (1990) trabalharam nas temáticas de eficiências relacionadas à diferenciação na alocação de recursos produtivos, destacando duas linhas importantes de eficiência: estática e dinâmica. A eficiência estática (alocativa ou ricardiana) avalia que a estrutura produtiva deve ser dirigida para os setores e produtos que possuem vantagens comparativas de custos, dadas as dotações de fatores em relação aos demais países por meio do comércio internacional, ou seja, o país ou região deve produzir aquilo que tem um menor custo produtivo comparado com outros países ou regiões. Esse enfoque é dito estático porque não incorpora a alteração do processo ao longo do tempo, assim, 
determinado país ou região será sempre fadado a produzir determinado produto específico e ficar restrito a este setor.

Já a eficiência dinâmica considera que o próprio processo produtivo pode ter efeitos positivos de produtividade e crescimento no tempo e também orienta sua estrutura produtiva para os setores com maiores conteúdos tecnológicos e com maior elasticidade-renda da demanda interna e externa. Isso ocorre porque considera que esses setores e produtos vivem em constante mudança e a estrutura da produção também apresentará uma eficiência dinâmica no tempo.

Assim, quando uma economia orienta sua estrutura produtiva para setores mais inovativos, que possuem elevado conteúdo tecnológico e que apresentam elevados níveis de produtividade, retornos crescentes e externalidades positivas, ela é chamada de economia com padrão de eficiência schumpeteriana.

Portanto, um desafio para a Região Centro-Oeste é promover uma mudança estrutural produtiva no sentido de diminuir relativamente a dependência de setores ou produtos com eficiência alocativa que são estáticos, sem retornos crescentes de escala, com baixa perspectiva de elasticidade-renda da demanda interna e externa, baixo conteúdo inovativo e tecnológico - como é o caso do modelo agrícola exportador de baixo valor agregado, notadamente representado por exportações de grãos in natura - e elevar a produção nos setores e produtos com alto conteúdo tecnológico, alta elasticidade-renda da demanda interna e externa, com retornos crescentes de escala, com feedbacks positivos na economia, ganhos de produtividade e crescimento, auxiliando na formação de um círculo virtuoso de crescimento (como é o caso, por exemplo, de produtos industriais tecnológicos).

Revoluções tecnológicas e janelas de oportunidades para o crescimento

Schumpeter (1942/1984) destaca que um dos fatores fundamentais do sistema capitalista é o processo de mutação industrial. Esse processo surge dentro do sistema e incessantemente revoluciona a estrutura e a dinâmica econômica, destruindo a velha e criando uma nova. Essa constante evolução é nomeada destruição criativa. Várias pesquisas de estudiosos como Dosi (2006), Dosi, Pavitt e Soete (1990), Perez (1992, 2001 e 2004), Freeman e Soete (1997) e Arend (2012) apontam que os 
países podem elevar suas possibilidades de crescimento se conseguirem aproveitar janelas de oportunidades que podem surgir nas revoluções tecnológicas, pois, com o surgimento de novos paradigmas tecnológicos, grandes mudanças na distribuição internacional de atividades inovadoras e na competitividade internacional de cada economia, essas oportunidades emergem. Esse fato pode remodelar o padrão de vantagens e desvantagens tecnológicas entre os países e às vezes apresenta uma única "janela de oportunidade" para o surgimento de novas tecnologias e economias líderes.

De acordo com Arend (2012), quando ocorre uma irrupção de novas indústrias dinâmicas em conjunto com uma nova infraestrutura pode-se abrir uma possibilidade de novos investimentos que por sua vez tendem a resultar na possibilidade de uma densa transformação no modo de produção, sistemas produtivos e novos sistemas de gestão. Desse modo, ocorre uma mudança de paradigma a cada revolução tecnológica, que é caracterizada pela composição de princípios organizacionais e tecnológicos, que indica o modo mais efetivo de empregar a revolução tecnológica em curso e utilizar para modernizar os demais setores da economia, e podem "difundir-se" para toda atividade do país reestruturando e impulsionando qualquer instituição.

Vale registrar que os tipos de infraestruturas que se estabelecem em determinados lugares - perante o sistema de inovação que é instalado não dependem, apenas, do tipo e do volume de produção daquele lugar, mas, também, da destinação dessa produção, o que evidencia a necessidade de análise dos processos de circulação. (SANTOS, 2008, p. 61)

Os países líderes nessas revoluções tecnológicas tendem a se beneficiar dessa situação e experimentam um processo grande de crescimento econômico, como podemos constatar analisando o processo histórico que evidencia vários casos de superação do atraso. Nessa perspectiva, Arend (2012) argumenta que as duas primeiras revoluções (revolução industrial e era do vapor e das ferrovias, respectivamente) foram capitaneadas pela Inglaterra, já a quarta e quinta (era do petróleo, do automóvel e da produção em massa e era da informática e das telecomunicações, respectivamente), pelos EUA. Países como Bélgica, França e EUA conseguiram o processo de catching up (processo de alcance do nível de riqueza dos países desenvolvidos) na segunda revolução. A terceira revolução (era do aço, da eletricidade e da engenharia pesada) apresentou uma característica peculiar por ser liderada por vários países como Inglaterra, EUA e Alemanha. Já na quinta revolução, países como 
Japão e Coreia do Sul ganharam destaque e experienciaram virtuosos processos de crescimento econômico.

As mudanças de paradigmas tecnológicos estão inseridas em um contexto de globalização da economia onde os lugares também se globalizam para atender a demandas de um novo sistema técnico hegemônico. Para Milton Santos (2008), além de um novo sistema técnico hegemônico tem-se, também, um novo sistema social hegemônico, que juntos resultam na criação do meio técnico-científico-informacional, que “(...) é um meio geográfico onde o território inclui obrigatoriamente ciência, tecnologia e informação”. (SANTOS, 2008, p. 41)

Na visão do autor, esse meio técnico-científico-informacional é a nova cara do tempo e do espaço, “(...) é aí que se instalam as atividades hegemônicas, aquelas que têm relações mais longínquas e participam do comércio internacional, fazendo com que determinados lugares se tornem mundiais”. E isso não se restringe à cidade; ciência, tecnologia e informação, mas também faz parte dos cotidianos do campo modernizado. (SANTOS, 2008, p. 41)

Sistemas de inovação e importância para o crescimento econômico

Os sistemas de inovação têm se mostrado elementos basilares e sustentáculos para o crescimento econômico dos países centrais. Segundo Albuquerque (1998), buscar um sistema nacional de inovação (SNI) "maduro" é muito relevante para que determinada economia consiga o catching-up e a superação do atraso econômico. Dentre os diversos autores que contribuem para uma melhor compreensão desses sistemas de inovação estão Nelson (1993) e Freeman (1988). De acordo com eles, esse sistema está relacionado com a criação e o fortalecimento institucional para cooperação, aprendizado e interações que criam um ambiente favorável à criação e difusão de novas tecnologias.

Outros estudos também auxiliam nesse campo, como os de Freeman (1995), Lundvall (1992), Edquist (2001) e Nelson (1993). Uma definição muito difundida foi formulada por Freeman (1995), que conceituou SNI como um conjunto de instituições, organizações, entidades e empresas que objetivam contribuir para a criação, absorção e difusão de inovações. Essas instituições podem ser universidades, empresas públicas e privadas, ministérios, institutos de pesquisa, agências, instituições financeiras, entre outras. 
Dentro desse contexto, Pattel e Pavitt (1994) destacam a importância de comparar os sistemas de inovação. Os autores apontam para uma tipologia com três diferentes categorias em relação aos países. Primeiramente, os sistemas de inovação que capacitam os países a se manterem na liderança do processo tecnológico internacional são chamados de sistemas maduros. Depois, temos os sistemas de inovação com objetivo de difusão de inovações, esses estariam em um patamar intermediário. Por fim, existem os países em que os sistemas de inovação não se completaram, ou seja, são os chamados sistemas incompletos.

Os sistemas incompletos estão naqueles países que construíram seu sistema de ciência e tecnologia, todavia, não os transformaram em sistemas de inovação, de fato. Esses países construíram uma infraestrutura básica, porém, caracterizam-se por uma pequena dimensão dessa estrutura, pela baixa articulação e pequena contribuição com o setor produtivo, assim, não extrapolam o patamar mínimo para serem enquadrados em um sistema de inovação. De acordo com os autores supracitados, alguns países que se destacam por possuírem esse tipo de SNI incompleto são Argentina, Brasil, México e Índia.

Os sistemas de difusão são caracterizados pelo elevado dinamismo tecnológico, pela grande capacidade de difusão, mas não pela capacidade de geração tecnológica. Por esse motivo, enquadram-se no nível intermediário de sistema de inovação. Alguns exemplos de países com esses sistemas são Coreia do Sul, Dinamarca, Holanda e Suécia. Já os sistemas maduros são os sistemas de inovação dos principais países capitalistas desenvolvidos. Esses sistemas são capazes de manter o país na fronteira tecnológica ou próximo a ela. Alguns exemplos de países que possuem um sistema de inovação maduro são Estados Unidos da América, Japão e Alemanha e muito próximos da fronteira tecnológica estão Inglaterra, França e Itália.

De acordo com o trabalho basilar de SNI para o caso brasileiro, Albuquerque (1996) busca entender qual a posição do país a respeito da situação do sistema de ciência e tecnologia. O autor discute que existe — em termos relativos - uma pequena dimensão do sistema brasileiro no que diz respeito ao pessoal envolvido, gastos gerais e composição da estrutura de gasto. Também aponta que existe uma ineficiência do sistema brasileiro em termos de patentes de invenções e publicações científicas; ademais, aponta que ocorre um padrão bastante inferior em relação aos sistemas maduros do envolvimento das empresas privadas e públicas com pesquisa e desenvolvimento (P\&D). 
Pereira e Dathein (2015) também analisaram a influência do comportamento inovativo das grandes empresas da indústria de transformação brasileira sobre a formação do SNI e não observam uma melhora do Brasil. Constataram, ainda, que o comportamento inovativo das empresas estrangeiras e nacionais não tem favorecido o desenvolvimento do SNI brasileiro.

Quanto à forma de difusão da inovação, Santos (2003) discute que existem dois tipos gerais de difusão. O primeiro deles é a relocalização, que consiste na mudança de determinados objetos alocados em um espaço para outro espaço. O segundo é a expansão, que consiste na difusão de objetos que têm uma localização inicial para outros espaços de objetos do mesmo tipo. Vale registrar ainda que, segundo Santos (2003, p. 63), mesmo que a difusão seja considerada, para muitos pesquisadores, como uma possibilidade de desenvolvimento, dá-se de forma seletiva de acordo com os interesses dos países desenvolvidos, "a difusão da inovação nunca se generaliza em todo o espaço periférico”.

\section{Análise de dados de ciência e tecnologia disponíveis para a Região Centro-0este}

Segundo Santos (2008, p. 135), a maior presença do meio técnicocientífico está nas regiões concentradas do Brasil, “(...) que cobre praticamente os Estados do Sul e do Sudeste e que desborda para o CentroOeste, como uma área contínua”. Segundo Silva (2011), "Os incentivos públicos e privados, recebidos pelo CO para uma produção voltada à exportação, foram condizentes com a lógica de acumulação capitalista emanada a partir da concentração de investimentos no Estado de São Paulo" nos anos 1970, o que contribuiu para o estabelecimento da divisão regional do trabalho no território nacional. De acordo com Santos (2008, p. 136), “(...) foi o período técnico-científico da humanidade, que permitiu, (...) que o que parecia um deserto, como o cerrado, (...) fosse transformado num vergel formado por um caleidoscópio de produções, a começar pela soja”.

A disponibilidade de dados e estatísticas no Brasil não é muito abundante, todavia, é possível inferir discussões a partir das informações disponíveis. Assim, a tabela 1 apresenta o número de doutores no Brasil por regiões de 2000 até 2014 . 
Tabela 1 - Número de doutores por regióes do Brasil (2000-2014)

\begin{tabular}{ccccccc}
\hline Ano & Norte & Nordeste & Sudeste & Sul & C0 & Total \\
\hline $\mathbf{2 0 0 0}$ & 705 & 3.705 & 17.354 & 5.034 & 1.873 & 27.662 \\
$\mathbf{2 0 0 2}$ & 1.152 & 5.168 & 20.540 & 7.165 & 2.404 & 34.349 \\
$\mathbf{2 0 0 4}$ & 1.721 & 7.294 & 28.837 & 10.312 & 3.632 & 47.971 \\
$\mathbf{2 0 0 6}$ & 2.313 & 9.380 & 33.900 & 12.711 & 4.339 & 57.586 \\
$\mathbf{2 0 0 8}$ & 2.863 & 11.625 & 38.558 & 14.931 & 5.379 & 66.785 \\
$\mathbf{2 0 1 0}$ & 3.877 & 15.445 & 45.991 & 18.516 & 7.400 & 81.725 \\
$\mathbf{2 0 1 4}$ & 6.863 & 26.467 & 66.702 & 28.612 & 11.628 & 133.409 \\
\hline
\end{tabular}

Fonte: $\mathrm{CNPq} / \mathrm{AEI}$. Diretório dos Grupos de Pesquisa no Brasil — número de pesquisadores doutores cadastrados nos censos do diretório, sem dupla contagem (2017).

Pelos dados da tabela 1, podemos verificar que o número de doutores no Brasil cresceu aproximadamente 382\% no período de 2000 até 2014. Nesse contexto, a Região CO obteve uma elevação ainda maior de aproximadamente $520 \%$, saindo de 1.873 para 11.628 doutores, no entanto, esse aumento não é seguido, necessariamente, de avanços tecnológicos, somente um estudo mais apurado dessas pesquisas e suas capilaridades, demonstrariam os reais efeitos e/ou potenciais de avanços para a ciência e a tecnologia na Região. Vejamos então o número de doutores relativamente à população por regiões do Brasil.

Gráfico 1 - Número de doutores por regióes do Brasil por 100 mil habitantes (2000-2014)

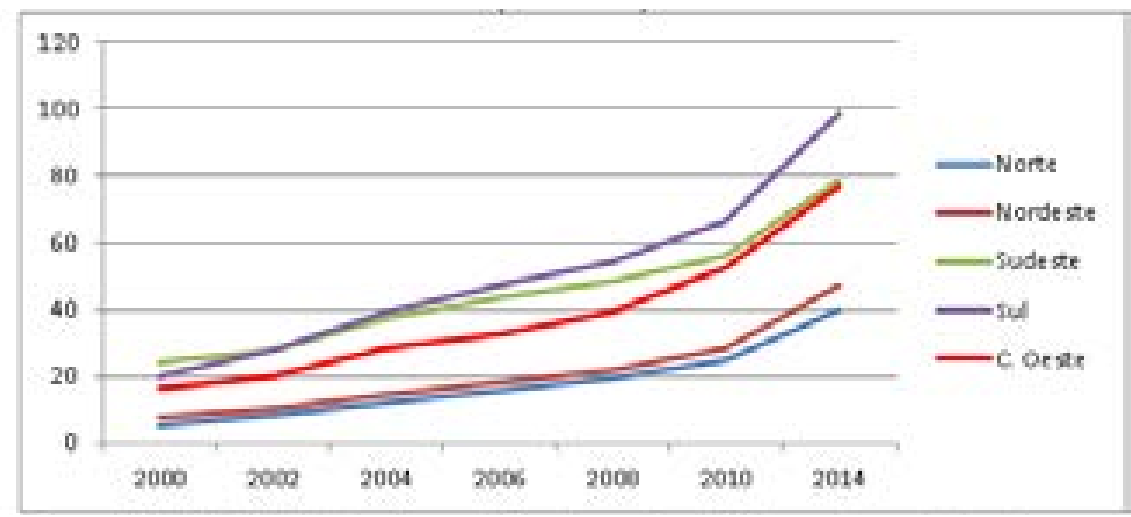

Fonte: $\mathrm{CNPq} / \mathrm{AEI}$. Diretório dos Grupos de Pesquisa no Brasil — número de pesquisadores doutores cadastrados nos censos do diretório, sem dupla contagem (2017). 
Com uma amostra que vai até o ano de 2014 é possível observar que ocorreu uma evolução no período e a Região CO se distanciou das regiões Nordeste e Norte e se aproximou da Sudeste. É importante destacar a importância relativa da Região Sul, que em quantidade absoluta fica atrás da Sudeste, mas por 100 mil habitantes assume a liderança isolada. Para obter um panorama mais atual da realidade de doutores no Brasil e da região CO é interessante observar os dados advindos da Plataforma Lattes, disponibilizada pelo CNPQ, que aqui servem como indicativos.

\section{Gráfico 2 - Participação das regióes do Brasil no número total de doutores no Brasil (2016)}

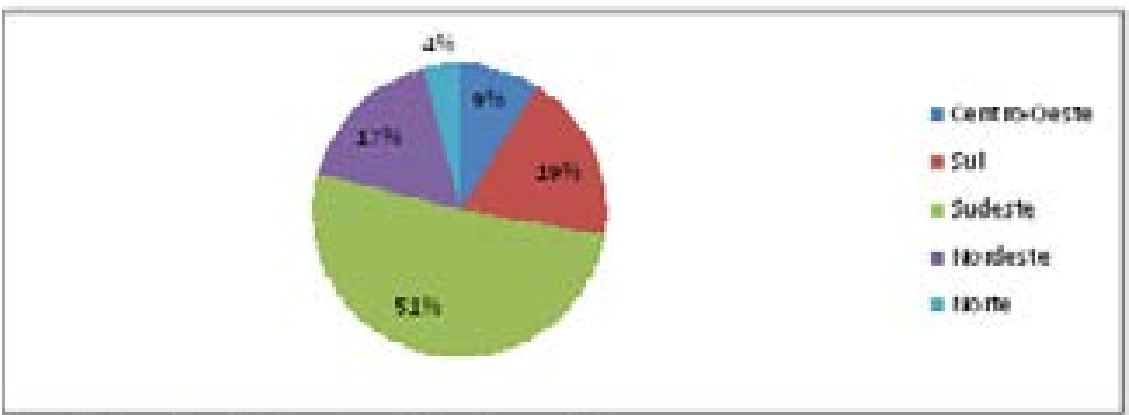

Fonte: elaboração própria baseada em Painel Lattes (2017).

Na tendência da tabela 1, mas agora analisando o ano de 2016, a Região Sudeste concentra a maior quantidade de doutores do país com $51 \%$, seguida por Sul, Nordeste, Centro-Oeste e Norte, respectivamente. A desigualdade da distribuição no território dos doutores dentro da região CO é constatada ao se observar que o Distrito Federal possui, aproximadamente, metade dos doutores da região, seguido de Goiás, com 23\%, Mato Grosso e Mato Grosso do Sul, esses últimos empatados com $14 \%$.

A tabela 2 apresenta um panorama da Região Centro-Oeste em comparação com o Brasil no que diz respeito a número de instituições, grupos, recursos humanos e linhas de pesquisa. 
Tabela 2 - Número de instituições, grupos, recursos humanos e linhas de pesquisa da Região CO e do Brasil (Censos 2000-2010)

\begin{tabular}{l||c|c|c|c|c|c||c|c|c|c|c|c}
\hline \hline $\begin{array}{l}\text { PRINCIPAIS } \\
\text { DIMENSÕES }\end{array}$ & \multicolumn{5}{|c|}{ REGIÃO CENTRO-OESTE } & \multicolumn{6}{|c|}{ BRASIL } & \\
\hline \hline & 2000 & 2002 & 2004 & 2006 & 2008 & 2010 & 2000 & 2002 & 2004 & 2006 & 2008 & 2010 \\
\hline \hline & 12 & 18 & 25 & 32 & 33 & 38 & 224 & 268 & 335 & 403 & 422 & 452 \\
\hline INSTITUIÇÕES & 636 & 809 & 1.139 & 1.275 & 1.455 & 1.965 & 11.760 & 15.158 & 19.470 & 21.024 & 22.797 & 27.523 \\
\hline GRUPOS & 3.187 & 3.948 & 6.002 & 7.011 & 8.416 & 11.656 & 48.781 & 56.891 & 77.649 & 90.320 & 104.018 & 128.892 \\
\hline PESQUISADORES & 1.873 & 2.404 & 3.632 & 4.339 & 5.379 & 7.400 & 27.662 & 34.349 & 47.973 & 57.586 & 66.785 & 81.726 \\
\hline $\begin{array}{l}\text { PESQUISADORES } \\
\text { DOUTORES }\end{array}$ & 3.676 & 3.348 & 6.287 & 8.064 & 10.421 & 14.687 & 59.357 & 61.872 & 102.913 & 141.630 & 160.931 & 213.433 \\
\hline ESTUDANTES & 962 & 1.035 & 1.208 & 1.131 & 1.273 & 1.658 & 16.769 & 18.380 & 22.733 & 23.159 & 24.143 & 27.484 \\
\hline TÉCNICOS & 2.231 & 2.831 & 4.157 & 4.664 & 5.568 & 7.669 & 38.126 & 50.473 & 67.903 & 76.719 & 86.075 & 106.715 \\
\hline $\begin{array}{l}\text { LINHAS DE } \\
\text { PESQUISA }\end{array}$ & & & & & & & & & & & & \\
\hline \hline
\end{tabular}

Fonte: CNPq/AEl. Diretório dos Grupos de Pesquisa no Brasil — número de pesquisadores doutores cadastrados nos censos do diretório, sem dupla contagem.

Podemos, assim, observar que ocorreu um avanço em todas as dimensões, tanto no CO como no Brasil. Relativamente, o CO conseguiu avanços, pois, no decorrer do período, saiu de uma participação no total brasileiro de 5\% no ano de 2000, na dimensão "Instituições", e avançou para 8\% no ano de 2010. Na dimensão “Grupos”, a evolução foi de 5\% para 7\% no mesmo período. Para "Pesquisadores e doutores", a participação no total brasileiro saiu de 7\% para 9\%. Entretanto, na dimensão "Estudantes", a evolução foi mais tímida, saiu de 6\% de participação no ano 2000 para 7\% em 2010. O número de técnicos ficou estagnado em 6\%, apresentando até uma queda na participação para 5\% de 2004 até 2008, mas voltou para $6 \%$ em 2010. As linhas de pesquisa tiveram uma evolução também tímida, de 6\% para 7\%.

Desse modo, podemos constatar que ocorreu um crescimento nas dimensões analisadas na tabela 2, o que demonstra ganhos relativos de participação do CO nas dimensões apresentadas do total brasileiro. Também é interessante observar os indicadores de produção científica da Região Centro-Oeste em comparação com o Brasil. 
Tabela 3 - Indicadores da produção científica dos pesquisadores doutores, 2010

\begin{tabular}{|c|c|c|c|c|c|c|c|}
\hline \multirow{2}{*}{\multicolumn{2}{|c|}{ Tipo de produção }} & \multicolumn{6}{|c|}{$\mathrm{N}^{0}$ de produções } \\
\hline & & $\begin{array}{l}\text { Quad. } \\
97-00\end{array}$ & $\begin{array}{l}\text { Quad. } \\
\text { 98-01 }\end{array}$ & $\begin{array}{l}\text { Quad. } \\
00-03\end{array}$ & $\begin{array}{l}\text { Quad. } \\
\text { 03-06 }\end{array}$ & $\begin{array}{l}\text { Quad. } \\
05-08\end{array}$ & $\begin{array}{l}\text { Quad. } \\
07-10\end{array}$ \\
\hline \multirow{12}{*}{ 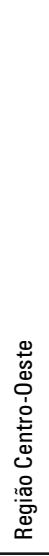 } & Produção bibliográfica & & & & & & \\
\hline & Número de autores & 1.704 & 2.312 & 3.484 & 4.170 & 5.069 & 6.746 \\
\hline & Artigos nacionais (1) & 4.220 & 6.639 & 12.439 & 15.208 & 19.590 & 27.953 \\
\hline & Artigos internacionais (2) & 3.545 & 5.121 & 6.756 & 10.488 & 13.040 & 18.968 \\
\hline & Trabalhos completos em anais & 5.159 & 7.759 & 12.837 & 19.129 & 22.293 & 28.564 \\
\hline & Livros & 599 & 874 & 1.234 & 1.632 & 1.952 & 2.505 \\
\hline & Capítulos de livros & 1.915 & 3.069 & 4.811 & 7.589 & 10.264 & 13.650 \\
\hline & Produção técnica & & & & & & \\
\hline & Número de autores & 790 & 1.259 & 2.039 & 3.145 & 4.370 & 6.121 \\
\hline & Softwares & 163 & 251 & 321 & 358 & 353 & 474 \\
\hline & Produtos & 127 & 185 & 320 & 488 & 484 & 711 \\
\hline & Processos & 41 & 106 & 239 & 385 & 395 & 440 \\
\hline \multirow{12}{*}{$\begin{array}{l}\overline{\bar{m}} \\
\stackrel{\bar{m}}{\omega} \\
\bar{\omega}\end{array}$} & Produção bibliográfica & & & & & & \\
\hline & Número de autores & 24.420 & 32.839 & 46.117 & 55.214 & 68.748 & 82.596 \\
\hline & Artigos nacionais (1) & 67.536 & 96.021 & 165.571 & 196.345 & 259.439 & 323.853 \\
\hline & Artigos internacionais (2) & 67.746 & 91.263 & 105.898 & 165.056 & 229.368 & 296.845 \\
\hline & Trabalhos completos em anais & 100.645 & 139.761 & 208.392 & 274.851 & 334.373 & 380.506 \\
\hline & Livros & 7.179 & 10.015 & 14.618 & 18.338 & 23.088 & 27.749 \\
\hline & Capítulos de livros & 26.333 & 40.152 & 64.629 & 94.017 & 133.254 & 165.049 \\
\hline & Produção técnica & & & & & & \\
\hline & Número de autores & 11.168 & 17.140 & 27.269 & 40.911 & 58.096 & 73.888 \\
\hline & Softwares & 2.503 & 3.466 & 5.010 & 5.432 & 5.425 & 6.141 \\
\hline & Produtos & 2.504 & 2.975 & 4.167 & 5.822 & 6.732 & 8.469 \\
\hline & Processos & 1.067 & 1.836 & 3.198 & 4.478 & 5.266 & 6.460 \\
\hline
\end{tabular}

Fonte: $\mathrm{CNPq} / \mathrm{AEI}$. Diretório dos Grupos de Pesquisa no Brasil — número de pesquisadores doutores cadastrados nos censos do diretório, sem dupla contagem.

Na comparação da Região Centro-Oeste com o Brasil é possível observar que ocorreram avanços relativos da região em todos os quesitos no período de 2000 até 2010 . O número de autores saiu de $7 \%$ para $8 \%$, artigos nacionais foram de $6 \%$ para 9\%, artigos internacionais saíram de $5 \%$ para $6 \%$, trabalhos completos em anais saíram de $5 \%$ para $8 \%$, 
livros, de 8\% para 9\%, capítulos de livros, de 7\% para 8\%. Em relação à produção técnica, as evoluções foram no número de autores, que foi de $7 \%$ para $8 \%$, softwares, de $7 \%$ para $8 \%$, produtos, de $5 \%$ para $8 \%$, e processos, de $4 \%$ para $7 \%$.

Destaque positivo para as produções técnicas, principalmente produtos e processos, ambas com evolução na participação nacional de três pontos percentuais no período.

Tabela 4 - Número de doutores por setor econômico cadastrados na Plataforma Lattes (2016)

\begin{tabular}{l|r|c}
\hline \multicolumn{1}{c|}{ Estado } & Total & Setor empresarial privado \\
\hline DF & 9.442 & 61 \\
GO & 4.486 & 39 \\
MT & 2.600 & 6 \\
MS & 2.767 & 6 \\
\hline \hline
\end{tabular}

Fonte: elaboração própria baseada em Painel Lattes (2017).

Um importante indicativo do sistema de inovação é justamente observar o emprego de doutores no setor empresarial produtivo; quando observamos o número de doutores que trabalham no setor empresarial privado, cadastrados na Plataforma Lattes, verificamos que a quase totalidade dos doutores da região não estão trabalhando em pesquisa e desenvolvimento nas empresas privadas. Esse indicador está em linha com o observado no Brasil de acordo com CGEE (2017) -- a maioria dos mestres e doutores estão trabalhando na administração pública federal e estadual, principalmente em universidades.

Todavia, o agravante para a Região CO é a magnitude, ou seja, um percentual muito baixo está no setor empresarial privado. De um modo geral, a Região Centro-Oeste apresentou melhoras no número de doutores, instituições, grupos de pesquisa, estudantes, produções bibliográficas e técnicas, sendo que em muitas áreas ocorreu um ganho de participação no total nacional. Todavia, algumas mazelas que também são observadas na realidade nacional aparecem na região, como a baixa presença de doutores no setor empresarial privado e também concentração dos atores de ciência e tecnologia geograficamente no território. 
Apesar de esses dados terem demonstrado avanços sobre a participação da ciência no desenvolvimento tecnológico no período técnico-científico na Região CO, Santos (1988, p. 7) nos alerta sobre a análise que deve ser feita da interdependência entre a ciência e a técnica, “já que sua utilização universal, quase sempre sem relação com os recursos naturais e humanos locais, é causa de graves distorções. Ora, tudo isso só foi possível, porque o trabalho científico foi praticamente colocado a serviço da produção".

Setor produtivo e atividades de inovação na Região Centro-0este

Alguns indicadores podem auxiliar na compreensão do envolvimento e da participação do setor produtivo em atividades de inovação. A tabela 5 revela o total de empresas e as empresas que implementaram produtos novos ou substancialmente aprimorados.

Tabela 5 - Total das empresas da indústria extrativa e de transformação e as que implementaram produtos, por faixas de participação percentual dos produtos novos ou substancialmente aprimorados no total das vendas internas, segundo as grandes regióes e unidades da federação selecionadas - Brasil (2014)

\begin{tabular}{|c|c|c|c|c|c|}
\hline \multirow{4}{*}{$\begin{array}{l}\text { Grandes regiões e } \\
\text { unidades da federação } \\
\text { selecionadas }\end{array}$} & \multicolumn{5}{|c|}{ Empresas } \\
\hline & \multirow{3}{*}{ Total } & \multicolumn{4}{|c|}{ Que implementaram produtos } \\
\hline & & \multirow[t]{2}{*}{ Total } & \multicolumn{3}{|c|}{$\begin{array}{l}\text { Faixas de participação percentual dos produtos novos } \\
\text { ou substancialmente aprimorados no total das vendas } \\
\text { internas }\end{array}$} \\
\hline & & & Menos de 10 & De 10 a 40 & Mais de 40 \\
\hline Brasil & 117.976 & 21.557 & 4.179 & 9.961 & 7.416 \\
\hline Norte & 3.830 & 846 & 90 & 487 & 268 \\
\hline Nordeste & 14.306 & 2.805 & 455 & 1.347 & 1.003 \\
\hline Sudeste & 60.423 & 10.131 & 2.083 & 4.489 & 3.559 \\
\hline Sul & 32.501 & 7.053 & 1.386 & 3.268 & 2.398 \\
\hline Centro-0este & 6.915 & 723 & 164 & 370 & 189 \\
\hline
\end{tabular}

Fonte: adaptado com base em IBGE, Diretoria de Pesquisas, Coordenação de Indústria, Pesquisa de Inovação - 2014 (2017). 
Enquanto no Brasil de um total de 117.976 empresas 21.557 implementaram inovações em produto, ou seja, aproximadamente 18\%, na Região CO, de um total de 6.915 empresas, 723 inovaram em produto, uma média de $10 \%$. Esses dados colocam a região em um patamar bastante ruim se comparado com a média nacional. Outro indicador nada satisfatório é que, das 723 empresas que inovaram, apenas $26 \%$ possuem faixa de participação dos produtos novos ou substancialmente aprimorados no total das vendas internas - acima de 40 (faixa de produtos novos) - enquanto no Brasil o percentual é de quase 35\%. Também é importante analisar quem é o principal responsável pelo desenvolvimento do produto e/ou processos com inovação, como pode ser observado na tabela 6 .

Tabela 6 - Principal responsável pelo desenvolvimento de produtos e/ou processos nas empresas das indústrias extrativa e de transformação que implementaram inovações, segundo as grandes regióes — Brasil (2012-2014)

\begin{tabular}{|c|c|c|c|c|c|c|c|c|}
\hline \multirow[b]{3}{*}{$\begin{array}{c}\text { Grandes } \\
\text { Regiões e } \\
\text { Unidades da } \\
\text { Federação } \\
\text { selecionadas }\end{array}$} & \multicolumn{8}{|c|}{$\begin{array}{l}\text { Principal responsável pelo desenvolvimento de produtos e/ou processos nas empresas que } \\
\text { implementaram inovações }\end{array}$} \\
\hline & \multicolumn{4}{|c|}{ Produto } & \multicolumn{4}{|c|}{ Processo } \\
\hline & $\begin{array}{c}\text { A } \\
\text { empresa }\end{array}$ & $\begin{array}{c}\text { Outra } \\
\text { empresa } \\
\text { do grupo }\end{array}$ & $\mid \begin{array}{c}\text { A empresa em } \\
\text { cooperação } \\
\text { com outras } \\
\text { empresas ou } \\
\text { institutos }\end{array}$ & $\begin{array}{c}\text { Outras } \\
\text { empresas } \\
\text { ou } \\
\text { institutos }\end{array}$ & $\begin{array}{c}\text { A } \\
\text { empresa }\end{array}$ & $\begin{array}{c}\text { Outra } \\
\text { empresa } \\
\text { do grupo }\end{array}$ & $\begin{array}{c}\text { A empresa } \\
\text { em } \\
\text { cooperação } \\
\text { com outras } \\
\text { empresas ou } \\
\text { institutos }\end{array}$ & $\begin{array}{c}\text { Outras } \\
\text { empresas } \\
\text { ou } \\
\text { institutos }\end{array}$ \\
\hline Brasil & 16.861 & 409 & 1.760 & 2.528 & 9.827 & 471 & 2.254 & 25.981 \\
\hline Norte & 747 & 35 & 25 & 39 & 579 & 19 & 52 & 945 \\
\hline Nordeste & 1.829 & 42 & 86 & 849 & 907 & 26 & 216 & 3.635 \\
\hline Sudeste & 7.934 & 255 & 935 & 1.007 & 5.347 & 350 & 1.075 & 11.440 \\
\hline Sul & 5.769 & 73 & 605 & 605 & 2.635 & 65 & 819 & 8.310 \\
\hline Centro-0este & 582 & 4 & 109 & 28 & 359 & 11 & 93 & 1.650 \\
\hline
\end{tabular}

Fonte: adaptado com base em IBGE, Diretoria de Pesquisas, Coordenação de Indústria, Pesquisa de Inovação — 2014 (2017).

As inovações de produtos geralmente são efetuadas pela própria empresa tanto no Brasil como na Região CO, porém, as inovações de processo são efetuadas, em sua maioria, por outras empresas ou 
instituições. Um elemento importante para o sistema de inovação seria uma maior protagonismo na cooperação entre empresas e institutos, todavia, tanto nas inovações de produto como nos processos essa realidade é oposta, ou seja, a cooperação não está impulsionando as inovações na Região CO.

Tabela 7 - Pessoas ocupadas nas atividades internas de pesquisa e desenvolvimento das empresas das indústrias extrativa e de transformação que implementaram inovações, por ocupação e por nível de qualificação, segundo as grandes regiões — Brasil (2014)

\begin{tabular}{|c|c|c|c|c|c|c|c|c|}
\hline \multirow{3}{*}{$\begin{array}{c}\text { Grandes } \\
\text { regiões e } \\
\text { unidades da } \\
\text { federação } \\
\text { selecionadas }\end{array}$} & \multirow{3}{*}{$\begin{array}{c}\text { Empresas que } \\
\text { implementaram } \\
\text { inovações de } \\
\text { produtos e/ou } \\
\text { processos }\end{array}$} & \multicolumn{7}{|c|}{$\begin{array}{l}\text { Pessoas ocupadas nas atividades internas de pesquisa e desenvolvimento das } \\
\text { empresas que implementaram inovações, por nível de qualificação }\end{array}$} \\
\hline & & \multirow{2}{*}{ Total } & \multicolumn{3}{|c|}{ Pesquisadores } & \multicolumn{2}{|c|}{ Técnicos } & \multirow{2}{*}{ Auxiliares } \\
\hline & & & $\begin{array}{c}\text { Pós- } \\
\text { graduados }\end{array}$ & Graduados & $\begin{array}{c}\text { Nível médio ou } \\
\text { fundamental }\end{array}$ & Graduados & $\begin{array}{l}\text { Nível médio ou } \\
\text { fundamental }\end{array}$ & \\
\hline Brasil & 42.987 & 105.267 & 7.768 & 45.792 & 12.556 & 14.903 & 14.324 & 9.923 \\
\hline Norte & 1.661 & 2.982 & 139 & 1.446 & 399 & 512 & 169 & 317 \\
\hline Nordeste & 5.314 & 4.337 & 558 & 1.301 & 734 & 470 & 794 & 480 \\
\hline Sudeste & 20.354 & 66.804 & 5.781 & 31.412 & 5.977 & 9.625 & 7.782 & 6.226 \\
\hline Sul & 13.370 & 28.450 & 1.188 & 10.669 & 4.810 & 3.754 & 5.380 & 2.649 \\
\hline Centro-0este & 2.288 & 2.694 & 103 & 965 & 636 & 541 & 198 & 251 \\
\hline
\end{tabular}

Fonte: adaptado com base em IBGE, Diretoria de Pesquisas, Coordenação de Indústria, Pesquisa de Inovação - 2014 (2017).

A partir da tabela 7, podemos notar que a maioria dos pesquisadores e técnicos que estão ocupados nas atividades internas de pesquisa e desenvolvimento das empresas das indústrias extrativa e de transformação que implementaram inovações são graduados. Os pós-graduados, quando se trata de pesquisa, correspondem a apenas 7,3\% do total no Brasil e apenas $3,8 \%$ na Região CO, ou seja, as atividades de pesquisa e desenvolvimento, tanto técnicas como de pesquisas, são realizadas, em sua maioria, por graduados ou por profissionais com nível de escolaridade inferior. 
Tabela 8 - Empresas das indústrias extrativa e de transformação, totais e as que realizaram dispêndios nas atividades internas de pesquisa e desenvolvimento, com indicação do número de pessoas ocupadas, segundo as grandes regiões — Brasil (2014)

\begin{tabular}{|c|c|c|c|c|c|c|}
\hline \multirow{4}{*}{$\begin{array}{l}\text { Grandes } \\
\text { regiões e } \\
\text { unidades da } \\
\text { federação } \\
\text { selecionadas }\end{array}$} & \multicolumn{6}{|c|}{ Empresas } \\
\hline & \multirow[t]{3}{*}{ Total } & \multirow{3}{*}{$\begin{array}{c}\text { Número de } \\
\text { pessoas } \\
\text { ocupadas em } \\
31.12(1)\end{array}$} & \multicolumn{4}{|c|}{$\begin{array}{l}\text { Que realizaram dispêndios nas atividades internas pesquisa e } \\
\text { desenvolvimento }\end{array}$} \\
\hline & & & \multirow[t]{2}{*}{ Total } & \multicolumn{3}{|c|}{$\begin{array}{l}\text { Número de pessoas ocupadas em pesquisa e } \\
\text { desenvolvimento }\end{array}$} \\
\hline & & & & Total (2) & $\begin{array}{l}\text { Com dedicação } \\
\text { exclusiva }\end{array}$ & $\begin{array}{l}\text { Com dedicação } \\
\text { parcial }\end{array}$ \\
\hline Brasil & 117.976 & 7.991.192 & 42.987 & 76.243 & 61.282 & 39.072 \\
\hline Norte & 3.830 & 276.033 & 1.661 & 2.186 & 1.890 & 1.050 \\
\hline Nordeste & 14.306 & 943.780 & 5.314 & 3.413 & 3.057 & 1.043 \\
\hline Sudeste & 60.423 & 4.478 .762 & 20.354 & 50.568 & 41.613 & 22.066 \\
\hline Sul & 32.501 & 1.967 .328 & 13.370 & 18.638 & 13.610 & 13.757 \\
\hline Centro-Oeste & 6.915 & 325.289 & 2.288 & 1.437 & 1.113 & 1.156 \\
\hline
\end{tabular}

Fonte: adaptado com base em IBGE, Diretoria de Pesquisas, Coordenação de Indústria, Pesquisa de Inovação — 2014 (2017).

Na elaboração da tabela 8 foram consideradas as empresas que implementaram produtos e/ou processos novos ou substancialmente aprimorados. Para tanto, foram tomados como parâmetro o número de pessoas ocupadas em 31/12, estimado a partir dos dados da amostra da Pesquisa Industrial Anual - Empresa 2011, bem como o total de pessoas ocupadas em dedicação plena nas atividades de pesquisa e desenvolvimento, obtido a partir da soma do número de pessoas em dedicação exclusiva e do número de pessoas em dedicação parcial, ponderado pelo percentual médio de dedicação.

Dessa perspectiva, a tabela apresenta as empresas das indústrias extrativa e de transformação que realizaram dispêndios nas atividades internas de pesquisa e desenvolvimento, destacando o número de pessoas ocupadas nessas atividades com dedicação exclusiva e com dedicação parcial. No Brasil, como nas demais regiões, o número de pessoas ocupadas em pesquisa e desenvolvimento com dedicação exclusiva é significativamente maior do que com dedicação parcial. Já na Região CO, o quantitativo entre as pessoas com dedicação exclusiva e parcial é muito próximo, o que pode ser um ponto desfavorável para a região, pois 
o número de pessoas que se dedicam exclusivamente à pesquisa e ao desenvolvimento é relativamente menor comparado com as outras regiões.

Tabela 9 - Grau de novidade do principal produto nas empresas das indústrias extrativa e de transformação que implementaram inovações, segundo as grandes regióes - Brasil (2012-2014)

\begin{tabular}{|c|c|c|c|c|c|c|c|c|c|}
\hline & \multicolumn{9}{|c|}{ Produto } \\
\hline & \multicolumn{3}{|c|}{$\begin{array}{l}\text { Novo para a empresa, mas já } \\
\text { existente no mercado nacional }\end{array}$} & \multicolumn{3}{|c|}{$\begin{array}{l}\text { Novo para o mercado nacional, mas } \\
\text { já existente no mercado mundial }\end{array}$} & \multicolumn{3}{|c|}{ Novo para o mercado mundial } \\
\hline $\begin{array}{c}\text { Brasil e } \\
\text { grandes } \\
\text { regiões }\end{array}$ & Total & $\begin{array}{l}\text { Aprimora- } \\
\text { mento } \\
\text { de um já } \\
\text { existente }\end{array}$ & $\begin{array}{l}\text { Completa- } \\
\text { mente } \\
\text { novo para } \\
\text { a empresa }\end{array}$ & Total & $\begin{array}{l}\text { Aprimora- } \\
\text { mento } \\
\text { de um já } \\
\text { existente }\end{array}$ & $\begin{array}{l}\text { Completa- } \\
\text { mente } \\
\text { novo para } \\
\text { a empresa }\end{array}$ & Total & $\begin{array}{l}\text { Aprimora- } \\
\text { mento } \\
\text { de um já } \\
\text { existente }\end{array}$ & $\begin{array}{l}\text { Completa- } \\
\text { mente } \\
\text { novo para } \\
\text { a empresa }\end{array}$ \\
\hline \multicolumn{10}{|l|}{ Brasil } \\
\hline & 17.000 & 8.943 & 8.057 & 4.064 & 2.193 & 1.871 & 493 & 240 & 253 \\
\hline Norte & 725 & 495 & 230 & 108 & 83 & 26 & 12 & 7 & 5 \\
\hline Nordeste & 2.620 & 1.098 & 1.522 & 153 & 85 & 69 & 31 & 24 & 7 \\
\hline Sudeste & 7.429 & 3.916 & 3.513 & 2.436 & 1.228 & 1.209 & 265 & 105 & 160 \\
\hline Sul & 5.586 & 3.118 & 2.469 & 1.287 & 763 & 524 & 180 & 104 & 76 \\
\hline $\begin{array}{r}\text { Centro- } \\
\text { Oeste }\end{array}$ & 639 & 316 & 323 & 79 & 35 & 44 & $\mathbf{5}$ & - & 5 \\
\hline
\end{tabular}

Fonte: adaptado com base em IBGE, Diretoria de Pesquisas, Coordenação de Indústria, Pesquisa de Inovação — 2014 (2017).

Um ponto relevante observado na tabela 9 diz respeito ao produto novo para o mercado mundial nas empresas das indústrias extrativa e de transformação que implementaram inovações, tendo em vista que, do total desses produtos, $100 \%$ foram completamente novos na Região CO, enquanto no Brasil esse percentual gravitou na ordem de 51\%. Entretanto, em linhas gerais, os dados revelam que, quanto maior o grau de novidade do produto, menor é o quantitativo de produtos; isso pode evidenciar indícios de que, mesmo entre as empresas que implementaram inovações, essas estão mais focadas em difusão de inovações existentes do que realmente em criação.

Esse resultado pode estar em consonância com Pereira e Dathein (2015), que, após análise, observaram que as empresas brasileiras possuem certa "reação adaptativa" ao que acontece em âmbito internacional e se caracterizam, muitas vezes, como "seguidoras" das estratégias inovativas das empresas estrangeiras. 
Também de acordo com a IBGE-PINTEC-2014 (2017), tratando das indústrias extrativa e de transformação que implementaram inovações no ano de 2014 no Brasil, 5,8\% realizaram atividades em biotecnologia e 2,19\% em nanotecnologia; já na Região CO, os valores foram 12,9\% e $3,14 \%$, respectivamente, observando-se um dado positivo para a região em atividades de biotecnologia. Em relação aos obstáculos, na Região CO os principais empecilhos apontados pelas empresas para inovar foram a escassez de fontes apropriadas de financiamento, elevados custos da inovação, riscos econômicos excessivos, escassas possibilidades de cooperação com outras empresas/instituições, falta de pessoal qualificado e falta de informação sobre tecnologia, em uma demonstração de que a região ainda tem muitos gargalos para serem resolvidos.

Das indústrias extrativa e de transformação que implementaram inovações no ano de 2014 na Região CO, 37\% receberam algum tipo de apoio governamental, número próximo da média nacional, que ficou em $40 \%$. Um destaque da região foi o financiamento para a compra de máquinas e equipamentos utilizados para inovar, entretanto, apenas $0,9 \%$ foram para projetos de pesquisa e desenvolvimento e inovação tecnológica, em parceria com universidades. Isso dá indícios da baixa cooperação entre universidades e setor produtivo na região.

Ainda de acordo com IBGE-PINTEC-2014 (2017), das indústrias extrativa e de transformação que implementaram inovações, apenas $13,24 \%$ cooperaram com outras organizações, totalizando 303 empresas. No entanto, entre essas empresas a cooperação com grau de importância de maior destaque ficou com os fornecedores e não com as universidades e institutos de pesquisa, tendo em vista que, de acordo com a fonte de informação, foi possível evidenciar que as principais, na Região CO, foram redes de informação informatizadas, fornecedores, consumidores e feiras e exposições, tendo as universidades e institutos de pesquisa ou centros tecnológicos desempenhado um papel menor.

Portanto, as atividades de inovação na Região CO relacionadas ao setor produtivo podem ser, de um modo geral, caracterizadas por estarem abaixo da média nacional no percentual de inovação em produto; por estarem, percentualmente, abaixo da média brasileira na quantidade de empresas que possuem mais de $40 \%$ de faixas de participação percentual dos produtos novos ou substancialmente aprimorados no total das vendas internas; por estarem com pouco protagonismo na cooperação 
entre empresas, universidades e institutos de pesquisa, por estarem com baixa participação de pós-graduados entre os pesquisadores que exercem atividade de pesquisa e desenvolvimento; e por estarem com menor percentual de pessoas com dedicação exclusiva ocupadas com pesquisa e desenvolvimento nas empresas.

É importante destacarmos que, mesmo entendendo que o desenvolvimento de um sistema de inovação maduro é um importante mecanismo capaz de impulsionar o desenvolvimento econômico e tecnológico da Região Centro-Oeste e, por conseguinte do Brasil, uma teoria que centra sua proposta apenas na tecnologia como mecanismo garantidor do desenvolvimento econômico se fragiliza ao não trazer as estruturas sociais para o debate. Nesse contexto é importante registrar as contribuições de Santos (2008, pp. 123-125) quando destaca que, além dos elementos fundamentais para a análise geográfica, como população, produção agrícola e industrial, transportes e comunicação, serviços públicos e privados, é necessário, que se insiram na análise geográfica os quatro grupos abaixo:

1. Problemas gerais: envolvem os componentes técnicos e científicos da atividade agrícola, novas atividades e localizações das atividades industriais, mudanças territoriais na base produtiva, modificações recentes na rede de transportes, financeirização do território, tendências à concentração e à centralização de atividades econômicas, complicação nos sistemas de cooperação e os novos papéis definidos para as cidades;

2. Relações cidade-campo: devem ser observados os novos insumos e seu fornecimento, deslocamento de atividades industriais para o campo, novas atividades de concepção, comando, administração e controle instalados em cidades médias ou pequenas, novos fluxos entre cidade-campo e novas formas de urbanização;

3. Relações interurbanas: compreendem análise nos novos consumos públicos e privados e seletiva de sua localização, os círculos de cooperação dos diversos níveis e sua interseção seletiva, o novo papel de entropia das metrópoles e seu papel na organização da região;

4. Organização interna das cidades e os novos papéis das metrópoles: envolve análise da tendência à dissolução da 
metrópole e as consequências da expansão territorial das regiões metropolitanas para a economia e a sociedade urbana.

\section{Considerações finais}

Para incentivar o crescimento econômico, consideramos ser importante uma mudança estrutural produtiva, acompanhada de fomento a produtos e setores com conteúdo tecnológico mais elevados, alinhada às revoluções tecnológicas. Dessa perspectiva, o objetivo deste artigo foi o de traçar um panorama da ciência e tecnologia da Região Centro-Oeste, observando se ela é capaz de impulsionar o desenvolvimento tecnológico na região em comparação com a realidade brasileira.

Em linhas gerais, no que diz respeito ao número de pesquisadores, instituições, artigos científicos publicados e número de doutores, ou seja, o lado "não produtivo no sentido econômico estrito", a Região Centro-Oeste apresentou diversos avanços, inclusive na comparação relativa ao Brasil, elevando o seu percentual de participação em diversos pontos. Todavia, quando analisamos o setor produtivo, observamos que algumas mazelas presentes no âmbito nacional são, muitas vezes, piores no Centro-Oeste.

Desse modo é possível afirmar que a ciência e a tecnologia na Região Centro- Oeste do Brasil obteviveram avanços, contudo, ainda não operam como um sistema de inovação completo no sentido de criação e fortalecimento institucional para a cooperação, aprendizado e interações, a fim de promover um ambiente favorável à geração e difusão de novas tecnologias em conjunto e integrado com o setor produtivo.

Alguns dos principais desafios a ser vencidos são: elevar a cooperação entre setor produtivo, empresas, universidades e institutos de pesquisa; buscar um maior ineditismo nos produtos inovadores; elevar o número de pós-graduados nos setores de pesquisa e desenvolvimento das empresas; elevar o percentual de pessoas ocupadas com pesquisa e desenvolvimento que possuam dedicação exclusiva. Além disso no que diz respeito ao apoio governamental —, não focar apenas os financiamentos de máquinas e equipamentos utilizados para inovar, mas, também, projetos de pesquisa e desenvolvimento e inovação tecnológica, em parceria com universidades e institutos de pesquisa. 


\section{Referências}

ALBUQUERQUE, E. M. Produção científica e sistema nacional de inovação. Ensaio FEE. Porto Alegre v. 19 n. 1 p. 156-180, 1998.

ALBUQUERQUE, E. da M. Sistema nacional de inovação no Brasil: uma análise introdutória a partir de dados disponíveis sobre a ciência e a tecnologia. Revista de Economia Política, São Paulo, v16, n.3, p 56-72, jul./set.1996.

AREND, Marcelo. Revoluções tecnológicas, finanças internacionais e estratégias de desenvolvimento: um approach neoschumpeteriano. Porto Alegre, Ensaios FEE, v. 33, n. 2, p. 363-396, nov. 2012.

CHOI, Hyeri; ZO, Hangjung. Assessing the efficiency of national innovation systems in developing countries. Science and Public Policy, OXFORD, Science and Public Policy, 46(4), 2019.

CGEE, Centro de Gestão e Estudos Estratégicos. Mestres e Doutores 2015 Estudos da demografia da base técnico-científica brasileira. Disponível em https://www.cgee.org.br/documents/10182/734063/Mestres Doutores 2015 Vs3. pdf. Acesso em: 19 de dezembro de 2017.

CNPq. Conselho Nacional de Desenvolvimento Científico e Tecnológico. Diretório dos Grupos de Pesquisa no Brasil. Grupos por ano de existência. Disponível em http://cnpq.br/indicadores1. Acesso em 18 de dezembro de 2017.

CNPq. Conselho Nacional de Desenvolvimento Científico e Tecnológico. Plataforma Lattes. 2016. Disponível em: http://estatico.cnpq.br/painelLattes/. Acesso em: 19 de dezembro de 2017.

DOSI, G. Mudança técnica e transformação industrial: a teoria e uma aplicação à indústria dos semicondutores. Campinas: Unicamp, 2006.

DOSI, G.; PAVITT, K.; SOETE, L. The economics of technical change and international trade. Harvester Wheatsheaf, 1990.

EDQUIST, C. The systems of innovation approach and innovation policy: an account of the state of art. DRUID Conference, 2001.

FREEMAN, C. The 'National System of Innovation' in historical perspective. Cambridge Journal of Economics, v. 19, pp. 5-24., 1995.

FREEMAN, C. Japan a new system of innovation. In: DOSI, G., FREEMAN, C., NELSON, R., eds. Technical change and economic theory. London: Pinter p.330-348. 1988.

FREEMAN, C.; SOETE, L. The economics of industrial innovation. Cambridge (MA): MIT Press. 1997.

IBGE. Instituto Brasileiro de Geografia e Estatística. Pesquisa de Inovação Tecnológica - PINTEC 2014. Rio de Janeiro. Disponível em: <http://www.ibge. gov.br>. Acesso em: 20/12/2017.

KWON, Seokbeom; MOTOHASHI, Kazuyuki. How institutional arrangements in the National Innovation System affect industrial competitiveness: A study of 
Japan and the US with multiagent simulation. Technological Forecasting and Social Change, v. 115, p. 221-235, 2017.

LUNDVALL, B.A. National systems of innovation: towards a theory of innovation and interactive learning. Londres, Pinter ed. 1992.

NELSON, R. National Innovation Systems - a Comparative Analysis. Oxford University Press, ed. 1993.

NELSON, R. National innovation systems: a comparative analysis. New York/ Oxford ed. Oxford University.1993.

PATEL, P; PAVITT, K. National Innovation Systems: Why they are Important, and how they might be Measured and Compared. Economics of Innovation and New Technology, 3: 77-95. 1994.

PEREIRA, A. J.; DATHEIN, R. Impactos do comportamento inovativo das grandes empresas nacionais e estrangeiras da indústria de transformação brasileira no desenvolvimento do Sistema Nacional de Inovação. Estudos Econômicos (São Paulo), v. 45, n. 1, p. 65-96, 2015.

PEREZ, C. Revoluciones tecnológicas y capital financiero: la dinâmica de las grandes burbujas financieras y las épocas de bonanza. México: Siglo XXI, 2004.

PEREZ, C. Cambio tecnológico y oportunidades de desarollo como blanco móvil. Revista de la CEPAL, Santiago de Chile, n. 75, p. 115-136, dic.2001.

PEREZ, C. Cambio técnico, restructuración competitiva y reforma institucional en los países en desarrollo. El trimestre económico, México, v. 1, n. 233, p. 2364, enero/marzo, 1992.

SANTOS, M. Economia espacial: críticas e alternativas. 2. ed. São Paulo: Edusp, 2003. Técnica, espaço, tempo: globalização e meio técnicocientífico-informacional. 5. ed. São Paulo: Edusp, 2008.

- Metamorfose do espaço habitado: Fundamentos teóricos e metodológicos da geografia. São Paulo: Hucitec, 1998.

SCHUMPETER, J. A. (1911). A Teoria do Desenvolvimento Econômico. São Paulo: Abril Cultural, 1982.

SCHUMPETER, J. A. (1942). Capitalismo, socialismo e democracia. Rio de Janeiro: Zahar, 1984.

SILVA, W. G. O processo de integração produtiva da região de Dourados à economia nacional. 2011. 204f. Tese (Doutorado em Geografia) - Programa de pós-graduação em Geografia Humana - Universidade de São Paulo. São Paulo: FFLCH, 2011.

WU, Jie; ZHUO, Shuaihe; WU, Zefu. National innovation system, social entrepreneurship, and rural economic growth in China. Technological Forecasting and Social Change, v. 121, p. 238-250, 2017.

ZHANG, Chao; WANG, Xiaojiong. The influence of ICT-driven innovation: a comparative study on national innovation efficiency between developed and emerging countries. Behaviour \& Information Technology, p. 1-11, 2019. 


\section{Contribuição Individual}

Todos os autores ofereceram substanciais contribuições científicas e intelectuais ao estudo. As tarefas de concepção e design do estudo, preparação e redação do manuscrito, bem como, revisão crítica foram desenvolvidas em grupo. O autor Mateus Boldrine Abrita ficou especialmente responsável pelo desenvolvimento teórico-conceitual; o segundo autor Walter Guedes da Silva, pela aquisição de dados e sua interpretação e análise.

Mateus Boldrine Abrita - Possui graduação em Ciências Econômicas pela Universidade Federal de Mato Grosso do Sul , mestrado em Ciências Econômicas pela Universidade pública em Maringá e Doutorado em Economia pela Universidade Federal do Rio Grande do Sul . Atualmente é professor efetivo da Universidade Estadual de Mato Grosso do Sul. ORCID: https://orcid.org/0000-0002-3327-4556

Walter Guedes da Silva - Licenciado e Bacharel em Geografia pela Universidade Federal de Mato Grosso do Sul, Licenciado em Pedagogia pelo Centro Universitário da Grande Dourados, Mestre em Desenvolvimento Sustentável pela Universidade de Brasília, Doutor em Geografia Humana pela Universidade de São Paulo, com pós-doutorado em estudos fronteiriços pela Universidade Federal de Mato Grosso do Sul. É professor Associado - Nível V - dos Cursos de Geografia, licenciatura e bacharelado, da Universidade Estadual de Mato Grosso do Sul. ORCID: https://orcid.org/0000-0001-6956-0119

Recebido para publicação em 1 de outubro de 2019 Aceito para publicação em 10 de novembro de 2019

Publicado em 06 de dezembro de 2019 